\title{
Genetic modification of livestock for the production of therapeutics and designer foods
}

\author{
PHIL L'HUILLIER \\ AgResearch, Ruakura Research Centre, Private Bag 3123, Hamilton, New Zealand
}

\begin{abstract}
The first transgenic animals were produced back in the mid-80s. This involved the introduction of foreign DNA into fertilised mouse eggs producing transgenic mice for studies of the biological systems regulating growth and development. Since that time, transgenic mice, rats, rabbits, sheep, pigs, goats and cattle have been produced. The use of transgenic animals for novel biomedical applications, such as the production of biologically important molecules or therapeutics, has now progressed to near-commercialisation. With the biological revelation that a cell taken from an adult animal can be developmentally-reprogrammed and, following transfer to an enucleated egg, produce a copy of the original donor animal came a new approach to the production of transgenic animals. This procedure, commonly referred to as nuclear transfer or 'cloning' now provides a new exciting and more sophisticated approach to the production of transgenic animals. These technologies and the livestock produced will have a significant impact on agriculture, livestock production, medicine and society as a whole. The current debate in our society about genetic engineering and genetically modified foods is indicative of the need to carefully identify the issues, and fully assess the benefits relative to the risks before embarking on commercial transgenic livestock production.
\end{abstract}

Keywords: biotechnology, cattle, genes, microinjection, molecular biology, nuclear transfer, nutraceuticals, pharmaceuticals, sheep, transgenic livestock

\section{Introduction}

Biotechnology is now considered by many to be the third revolution of our time, after the industrial and information technology eras. In the USA, biotechnology is expected to represent $20 \%$ of GDP by the year 2020 . At the present time, the impact on New Zealand is anticipated to be considerably less, at least in financial terms. However, the impact on the lives of people will nonetheless be significant through agricultural, food and medical applications of the biotechnology.
Biotechnology can be described as the industries and industrial processes that involve the use of advanced or recombinant (genetically modified) biological systems. It is perhaps easier to understand by considering a few current examples of how the technology is or can be applied. For instance, it provides new ways to produce drugs for human therapeutics, such as insulin for the treatment of diabetes. Genetically modified bacteria in fermentation-style vats now produce human insulin. Traditional approaches involved the extraction of porcine insulin from the pancreas of slaughterhouse pigs.

The development of genetically modified plants and animals for the agricultural, and in turn, the food and fibre industries are other applications of biotechnology. One of the most exciting areas of modern biotechnology is the genetic modification of plants and animals (transgenic organisms) to alter their physiology to produce foreign or transgenic molecules. Transgenic technology involves the transfer of a segment of DNA into the genetic material of another species. An example of a transgenic plant now familiar to most is the 'Roundup-ready' soya-bean from the Monsanto Corporation. A gene that provides resistance to the herbicide Glyphosate or Round-up has been incorporated into the plants.

The same technology offers the potential to insert or delete genes in animals also. Indeed, some biotechnology companies have taken advantage of the natural (and selected) ability of livestock such as cattle, sheep and goats to produce large quantities of protein in their milk. By combining this with genetic modification, new animals can be developed that produce large quantities of highly valuable proteins. This is done by inserting a copy of the foreign gene encoding the protein or drug into an embryo, which will develop into an animal. Once the animal is lactating, the new protein, just like the existing milk proteins, is produced in the milk from where it can be purified. For people who require human blood products or even insulin, the choice of sourcing their drugs from genetically modified organisms like these lessens the risk of HIV and other infectious diseases. Alternatively, the foreign gene may code for a protein that has advantageous nutritional or health properties, and the resulting milk be used ultimately for the production of 'functional or designer' foods. 


\section{Development and production of transgenic livestock}

The vast majority of transgenic livestock has been produced using the procedure of microinjection. Many of the scientific breakthroughs that enabled the production of these genetically modified animals have occurred over the previous two decades. The production of transgenic animals, in the form of mice, was first described in 1980 (Gordon et al. 1980). Since this time, the production of transgenic mice by microinjection of DNA into the pronucleus of zygotes has been the most productive and widely used technique. Likewise during the past 15-20 years, the technique of microinjecting DNA into a fertilised zygote has been extended to a variety of species beyond the mouse, including rats, rabbits, pigs, sheep, cattle, goats, and some species of fish and poultry (Pinkert \& Murray 1999).

\section{Pronuclear micro-injection}

The principal advantage of this technique is that the procedures are now relatively standard and well characterised for most livestock species. Further, although the efficiency of production of transgenic livestock is considerable lower than in mice, many transgenic animals are now 'on the ground' around the world.

The process of integration of the transgene (the injected DNA or gene construct) into the genome is still not well understood (Bishop \& Smith 1989; Hamada et al. 1993). However, it is clear that one to several hundred copies of the transgene are usually integrated at a unique and apparently random site. At least in mice, although these injections are performed in the pronuclei of fertilised eggs, it appears that the majority of founder animals are mosaic. This means that not all cells in the body of the founder transgenic animal contain the foreign injected DNA. This suggests that the DNA integrates into the mouse genome after the first cell division (Whitelaw et al. 1993). The practical consequence of this mosaicism is that the founder animals must be bred and expression of the transgene evaluated in the offspring. With cattle, this adds an additional 2-3 years on to the experimental time frame. The percentage of livestock born that are identified as transgenic varies widely between experiments and appears overall slightly lower than that observed in mice (1-15\% vs. $20-30 \%$ respectively).

Traditionally, the cost of production of transgenic livestock has been very high. This cost, when compared with mice, does not appear to reflect a difference in the efficiency of the microinjection technology applied to these species. It is rather related to the number of fertilised ova obtainable per female, the availability and the number of recipients needed for the microinjected eggs, the length of the gestation time, the generation interval, and the maintenance costs of these animals. In addition, for physiological reasons, oestrus synchronisation seems more difficult to achieve in farm animals as compared with mice. Despite this, the technology has already been applied successfully in cattle to produce transgenic animals (Krimpenfort et al. 1991; Hyttinen et al. 1994).

The cost of producing transgenic livestock could be lowered by transferring only developmentally-competent and/or transgenic embryos to donor females. This would reduce the number of synchronised recipients required, and therefore in the case of ruminants, lower the cost considerably. One approach for selection of viable eggs is to mature embryos from the one-two cell stage to morulae or blastocysts either in rabbit oviducts or in in vitro culture systems (Hyttinen et al. 1994; Krimpenfort et al. 1991). This approach enables the taking of biopsies for sexing and transgene analysis by polymerase chain reaction (PCR) prior to embryo transfer (Bowen et al. 1994; Fajfar-Whetstone et al. 1993; Hyttinen et al. 1994).

The site of integration of the transgene can have a major influence on the level of its expression. Thus, the level of expression of a transgene usually varies widely between lines of animals, and is largely unpredictable. The predictability of expression of a transgene can be improved by including dominant control elements in the gene construct or by using very large fragments of DNA that include all the regulatory regions.

\section{Embryonic stem cell manipulation}

Embryonic stem cells (ES cells) are totipotent cells derived from the embryonic inner cell mass of preimplantation embryos. They can be propagated and manipulated in vitro while retaining their ability to fully participate in embryonic development and thus produce viable animals. ES cells have been used mostly for deletion of target genes by homologous recombination (see Capecchi 1989) in mice for studies to characterise the function of specific genes. ES cells have also been used to introduce subtle genetic mutations (Askew et al. 1993; Stacey et al. 1994; Valancius \& Smithies 1991; Wu et al. 1994). However, this very powerful technology still appears to be limited to mice as true ES-cells have not yet been established for other species (see Anderson 1992, for a review). In hamsters (Doetschman et al. 1988) and pigs (Notarianni et al. 1990), ES-like cells that can be maintained in culture and undergo differentiation have been described. Similarly in rats, ES-like cells have shown to produce chimeras (Iannaccone et al. 1994), but their contribution to the germ-line remains to be demonstrated. Short-term in vitro culture of cells derived from the inner cell 
mass of blastocysts from cattle and the subsequent production of calves by transfer of nuclei from these cells into enucleated oocytes has already recently been reported (Sims \& First 1994). Thus to date, true ES cells have only been described and used in mice. This has severely limited the use of this very powerful approach to delete or in a site-specific manner insert genes into mice. However with the development of nuclear transfer procedures, gene deletion and sitespecific insertion should become possible in livestock.

\section{Other alternative strategies}

Germ-line transformation of animals can also be achieved using retroviruses. In mammals, the use of such vectors has, until recently, been mainly restricted to mice. However, Chan et al. (1998) used a retrovirus approach that resulted in impressive and promising advancement in the efficiency of production of transgenic cattle. Transfer of a retroviral replication-defective RNA vector into oocytes in MII arrest of meiosis, by pronuclear injection, resulted in the production of cattle offspring whereby the majority were transgenic.

The possibility of obtaining transgenic animals using spermatozoa to carry the foreign DNA into the egg has been achieved in a limited number of laboratories (Lavitrano et al. 1989; Gagné et al. 1991), and for a range of species (Rottmann et al. 1991; Schhellander et al. 1995; Sperandio et al. 1996). More recently, coinjection of unfertilised mouse oocytes with sperm heads (or membrane disrupted sperm) and exogenous DNA (encoding either a green fluorescent protein or Lac $Z$ reporter gene) into oocytes has resulted in about $20 \%$ of offspring expressing the integrated transgene (Perry et al. 1999). These data suggest that exogenous DNA can be reproducibly delivered into an oocyte by microinjected spermatozoa and provide a new and potentially inexpensive method for the production of transgenic animals. One of the problems of the 'spermmediated' approach for the production of transgenic animals is that the procedure results in a medium-high rate of mosaicism in the resulting founder transgenic animals (Chan 1999). Consequently, as for microinjection, this method necessitates the breeding of F1 animals to evaluate the expression of the transgene.

\section{Production of transgenic animals by nuclear transfer}

The relatively recent demonstration that livestock can be cloned using a procedure known as nuclear transfer is likely to revolutionise the production of transgenic animals. Further, this technology will, and has, raised many exciting scientific questions and observations. Perhaps the most far reaching to date is the observation that a fully differentiated cell from an adult animal can be 're-programmed' to generate a new viable animal.
Nuclear transfer in livestock is achieved by the fusion of a donor cell to an unfertilised egg or early embryo which has been enucleated (Wilmut et al. 1999; Wells et al. 1999). This procedure involves firstly deriving a cell line from an animal of interest. Such an animal maybe a high producing or rare adult cow, sheep, or goat. Similarly, the donor cell line can be derived from a foetus or embryonic source. This cell line needs to be totipotent for nuclear transfer (TNT). This means that it retains the ability to differentiate into all the different cell types (and organs) that make up the adult organism. Oocytes are then recovered, generally from ovarian samples collected from the slaughterhouse, and the chromosomal material is carefully removed. A totipotent cell is then injected into the enucleated oocyte and wedged between the zona pellucida and the cytoplast membrane (Wells et al. 1997). A small pulse of electricity is then applied to the reconstructed oocyte to fuse the membranes. The embryo is activated into development by chemical means, and is then cultured in vitro until the morula/ blastocyst stage. Viable embryos are transferred to synchronised recipient animals to develop to term.

Once permanent cell lines with totipotent nuclei have been established, there is in principle no limit to the genetic alterations that can be made. Transgenic sheep and cattle have been produced quickly by nuclear transfer of transformed fetal fibroblasts, demonstrating that this is a promising technique for the production of transgenic animals (Schnieke et al. 1997; Cibelli et al. 1998). Indeed, nuclear transfer is rapidly becoming the method of choice for the production of transgenic livestock. Using nuclear transfer, transgenic animals are developed firstly by transfecting the totipotent somatic cells with a gene construct of interest. 'Transgenic' cells are then selected, isolated and used as the donor nuclei source for nuclear transfer (see Figure 1).

\section{Application of transgenic animals}

\section{Traits affecting domestic animal productivity}

One of the first transgenic experiments performed involved the insertion of a growth hormone gene into mice. The body size and growth rates of the transgenic mice were dramatically affected by expression of a growth hormone gene under the control of a metallothionein enhancer/promoter (Palmiter et al. 1982). These experiments stimulated interest in modifying traits that determine productivity of domestic animals. Similar attempts to modify growth in sheep and pigs resulted in a range of phenotypes that, although included altered lean:fat body composition and feed conversion efficiency, also led to undesirable side-effects such as skeletal abnormalities and infertility (Pursel et al. 1989). 
Figure 1 Schematic diagram of steps involved in production of transgenic cattle using nuclear transfer or cloning procedures.

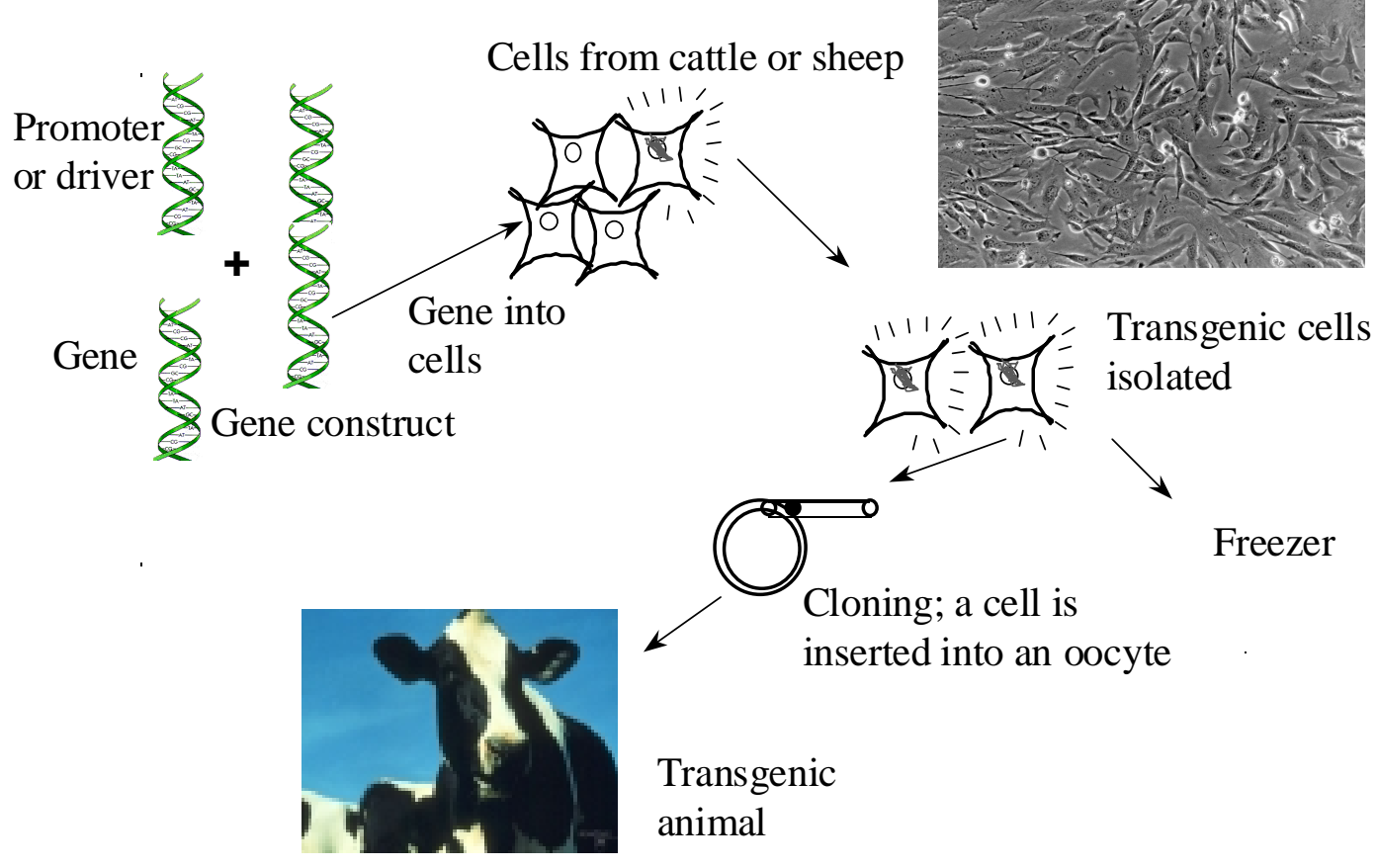

More recent attempts to manipulate growth of domestic animals have involved the insertion of genes such as $c$ $s k i$, growth hormone releasing factor and insulin-like growth factor I (IGF-I). These studies, whilst demonstrating that progress is being made towards producing animals with desirable growth and body compositional phenotypes, have further illustrated the need to develop a better understanding of the biology of muscle growth and development. Currently, a number of groups around the world (including one in New Zealand) are attempting to delete, or modify the expression of the myostatin gene in sheep and pigs. This gene has been found recently to be responsible for the double muscling phenotype in Belgian blue cattle. In sheep and pigs, the deletion may lead to advantageous changes in carcass composition.

Other productivity traits that are major targets for modification include characteristics of the milk of goats and cattle. Manipulation of the composition of endogenous milk proteins is likely to confer advantageous nutritional and/or processing properties on the milk. Some modifications that maybe beneficial include: (i) overexpression of milk protein genes such as $\kappa$-casein to reduce the size of casein micelles and thus improve the yield of cheese; (ii) expression of modified forms of milk protein genes such as $\beta$-casein without phosphate groups to yield a higher moisture and thus softer cheese; (iii) reduction or even inhibition of gene expression, such as $\alpha$-lactalbumin to reduce milk lactose content. For a more thorough review of possible beneficial changes that could be made to milk refer to Murray \& Maga (1999).

\section{Pharmaceuticals}

The concept of using livestock as 'bioreactors' for the production of high-value molecules has been around for at least a decade. This approach is founded on the biological ability of livestock (and in some cases rabbits) to produce large quantities of protein in their milk. A foreign gene is insertion into the animal under the control of regulatory elements or a promoter that directs expression of the gene to the lactating mammary gland. Milk is harvested from the lactating transgenic animal and the high-value protein is purified from the milk. Table 1 shows some examples of current projects in this area and the stage with respect to clinical trialling. In general, many projects aimed at delivering pharmaceuticals from milk are considerably further advanced than those aiming towards production trait modifications. Technology developments are occurring at a much faster rate in the 'pharmaceuticals' area, and many of the first products to be commercialised will be from this area. 
Table 1 Examples of transgenic livestock for agricultural, nutraceutical or pharmaceutical applications.

\begin{tabular}{lccc}
\hline Gene & Target & Species & $\begin{array}{c}\text { Stage of } \\
\text { development }\end{array}$ \\
\hline Antithrombin III & Congential ATIII deficiency & Phase III clinical \\
Anti-cancer Mab & Cancer & Goats & Animal \\
Human Serum Albumin & Blood protein & Mouse & Animal \\
$\alpha-1$-antitrypsin & Cystic fibrosis & Sheep & Phase II clinical \\
Fibrinogen & Blood clotting factor & Sheep & Animal \\
Factor VIII & Blood clotting factor & Sheep/Goat & Phase I clinical \\
Human $\alpha$-lactalbumin & Neutraceutical (phenylketonuria) & Animal \\
Human lactoferrin & Neutraceutical & Cow & Animal \\
Human $\alpha$-glucosidase & Pompe's disease & Rabbits & Phase I/II \\
Bovine casein & Neutraceutical & Cow & Animal \\
Human myelin basic protein & Multiple sclerosis & Cow & Animal \\
\hline
\end{tabular}

\section{Transgenic livestock production in New Zealand}

Two organisations are working on the development of transgenic livestock in New Zealand. The first of these is the Scotland-based company PPL Therapeutics who have established a sheep farm in New Zealand. This farm or containment/quarantine facility is intended for the housing of sheep that are transgenic for $\alpha_{-1}$ antitrypsin. Recent approval for this work, granted by ERMA New Zealand, will allow PPL to scale the 'production' flock up to 10000 animals. The second organisation in New Zealand working on the development of transgenic livestock is AgResearch, where development of genetically modified cattle is currently being undertaken (see Table 1). In this case the target applications are both therapeutics, and potentially, functional foods.

\section{Conclusions}

The development of transgenic livestock is one of the most exciting areas of biotechnology. Already transgenesis has been applied to a wide range of species, and involves a large number of different genes. The ultimate product applications of the technology can be found in the agricultural, food and pharmaceutical industries. Technological changes are occurring rapidly; recent successes in 'cloning' are likely to revolutionise the development and precision by which transgenic livestock can be developed.

In New Zealand at the present time, the two organisations developing or handling transgenic livestock are both working within the confines of double-fenced containment facilities. This, in my view enables New Zealand to assess with minimal risk, the potential opportunities and benefits of this emerging technology.

\section{REFERENCES}

Anderson, G.B. 1992. Isolation and use of embryonic stem cells from livestock species. Animal biotechnology 3: 165-175.

Askew, G.R.; Doetschman, T.; Lingrel, J.B. 1993. Sitedirected point mutations in embryonic stem cells: A gene-targeting tag-and-exchange strategy. Molecular and cellular biology 13: 4115-4124.

Bishop, J.O.; Smith, P. 1989. Mechanism of chromosomal integration of micro-injected DNA. Molecular biology and medicine 6: 283-298.

Bowen, R.A.; Reed, M.; Schnieke, A.; Seidel, G.E.; Stacey, A.; Thomas, W.K.; Kajikawa, O. 1994. Transgenic cattle resulting from biopsied embryos: expression of c-ski in a transgenic calf. Biology of reproduction 50: 664-668.

Capecchi, M.R. 1989. The new mouse genetics: altering the genome by gene targeting. Trends in genetics 5 : $70-76$.

Chan, A.W.S. 1999. Transgenic animals: current and alternative strategies. Cloning 1: 25-46.

Chan, A.W.S.; Homan, E.J.; Ballou, L.U.; Burns, J.C;. Bremel, R.D. 1998. Transgenic cattle produced by reverse-transcribed gene transfer in oocytes. Proceedings of the National Academy of Sciences USA 95: 14028-14033.

Cibelli, J.B.; Stice, S.L.; Golueke, P.J.; Kane, J.F.; Jerry, J.; Blackwell, F.; Ponce de Leon, F.; Robl, J.M. 1998. Cloned transgenic calves produced from nonquiescent fetal fibroblasts. Science 280: 12561258.

Doetschman, T.; Williams, P.; Maeda, N. 1988. Establishment of hamster blastocyst-derived embryonic stem (ES) cells. Developmental biology 127: 224-227.

Fajfar-Whetstone, C.J.; Rayburn, A.L.; Schook, L.B.; Wheeler, M.B. 1993. Sex determination of porcine 
preimplantation embryos via Y-chromosome specific DNA sequences. Animal biotechnology 4: 183-193. Gagné, M.B.; Pothier, F.; Sirard, M.A. 1991. Electroporation of bovine spermatozoa to carry foreign DNA in oocytes. Molecular reproduction and development 29: 6-15.

Gordon, J.W.; Scangos, G.A.; Plotkin, D.J.; Barbosa, J.A.; Ruddle, F.H. 1980. Genetic transformation of mouse embryos by microinjection of purified DNA. Proceedings of the National Academy of Sciences USA 77: 7380-7384.

Hamada, T.; Sasaki, H.; Seki, R.; Sakaki, Y. 1993. Mechanism of chromosomal integration of transgenics in microinjected mouse eggs: Sequence analysis of genome-transgene and transgenetransgene junctions at two loci. Gene 128: 197202.

Hyttinen, J.M.; Peura, T.; Tolvanen, M.; Aalto, J.; Alhonen, L.; Sinervirta, R.; Halmekytö, M.; Myöhänen, S.; Jänne, J. 1994. Generation of transgenic dairy cattle from transgene-analysed and sexed embryos produced in vitro. Bio/Technology 12: 606608.

Iannaccone, P.M.; Taborn, G.U.; Garton, R.L.; Caplice, M.D.; Brenin, D.R. 1994. Pluripotent embryonic stem cells from the rat are capable of producing chimeras. Developmental biology 163: 288-292.

Krimpenfort, P.; Rademakers, A.; Eyestone, W.; van der Schans, A.; van den Broek, S.; Kooiman, P.; Kootwijk, E.; Platenburg, G.; Pieper, F.; Strijker, R.; de Boer, H. 1991. Generation of transgenic dairy cattle using "in vitro" embryo production. Bio/Technology 9: 845-847.

Lavitrano, M.; Camaioni, A.; Fazio, V.M.; Dolci, S.; Farace, M.G.; Spadafora, C. 1989. Sperm cells as vectors for introducing foreign DNA into eggs: genetic transformation of mice. Cell 57: 717-723.

Murray, J.D.; Maga, E.A. 1999. Changing the composition and properties of milk. pp. 193-208. In: Transgenic animals in agriculture. Eds. Murray, J.D.; Anderson, G.B.; Oberbauer, A.M.; McGloughlin, M.M.; Wallingford, CAB International.

Notarianni, E.; Laurie, S.; Moor, R.M.; Evans, M.J. 1990. Maintenance and differentiation in culture of pluripotential embryonic cell lines from pig blastocysts. Journal of reproduction and fertility 41: 5156.

Palmiter, R.D.; Brinster, R.L.; Hammer, R.E.; Trumbauer, M.E.; Rosenfeld, M.G.; Birnberg, N.C.; Evans, R.M. 1982. Dramatic growth of mice that develop from eggs microinjected with metallothionein-growth hormone fusion genes. Nature 300 : 611-615.
Perry, A.C.F.; Wakayama, T.; Kishikawa, H.; Kasai, T.; Okabe, M.; Toyoda, Y.; Yanagimachi, R. 1999. Mammalian transgenesis by intracytoplasmic sperm injection. Science 284: 1180-1183.

Pinkert, C.A.; Murray, J.D. 1999. Transgenic farm animals. pp. 1-18. In: Transgenic animals in agriculture. Eds. Murray, J.D.; Anderson, G.B.; Oberbauer, A.M.; McGloughlin, M.M. Wallingford, $\mathrm{CAB}$ International.

Pursel, V.G.; Pinkert, C.A.; Miller, K.F.; Bolt, D.J.; Campbell, R.G.; Palmiter, R.D.; Brinster, R.L.; Hammer, R.E. 1989. Genetic engineering of livestock. Science 244: 1281-1288.

Rottmann, O.J.; Antes, R.; Hoefer, P.; Maierhofer, G. 1991. Liposomes mediated gene transfer via spermatozoa into avian egg cells. Journal of animal breeding and genetics 109: 64-70.

Schellander, K.; Peli, J.; Schmall, F.; Brem, G. 1995. Artificial insemination in cattle with DNA-treated sperm. Animal biotechnology 6: 41-50.

Schnieke, A.E.; Kind, A.J.; Ritchie, W.A.; Mycook, K.; Scott, A.R.; Ritchie, M.; Wilmut, I.; Colman, A.; Campbell, K.H.S. 1997. Human factor IX transgenic sheep produced by transfer of nuclei from transfected fetal fibroblasts. Science 278: 2130-2133.

Sims, M.; First, N.L. 1994. Production of calves by transfer of nuclei from cultured inner cell mass cells. Proceedings of the National Academy of Sciences of the USA 90: 6143-6147.

Sperandio, S.; Lulli, V.; Bacci, M.L.; Forni, M.; Maione, B.; Spadafora, C.; Lavitrano, M. 1996. Spermmediated DNA transfer in bovine and swine species. Animal biotechnology 7: 59-77.

Stacey, A.; Schnieke, A.; McWhir, J.; Cooper, J.; Colman, A.; Melton, D.W. 1994. Use of doublereplacement gene targeting to replace the murine $\alpha$ lactalbumin gene with its human counterpart in embryonic stem cells and mice. Molecular and cellular biology 14: 1009-1016.

Wells, D.N.; Misica, P.M.; Tervit, H.R.; Vivanco, W.H. 1998. Adult somatic cell nuclear transfer is used to preserve the last surviving cow of the Enderby Island cattle breed. Reproduction fertility and development 10: 369-378.

Wells, D.N.; Misica, P.M.; Day, A.M.; Tervit, H.R. 1997. Production of cloned lambs from an established embryonic cell line: a comparison between in vivo- and in vitro-matured cytoplasts. Biology of reproduction 57: 385-393.

Wells, D.N.; Misica, P.M.; Tervit, H.R. 1999. Production of cloned calves following nuclear transfer with cultured adult mural granulosa cells. Biology of reproduction 60: 996-1005. 
Wilmut, I.; Schnieke, E.; McWhir, J.; Kind, A.J.; Colman, A.; Campbell, K.H.S. 1999. Nuclear transfer in the production of transgenic farm animals. pp. 67-68. In: Transgenic animals in agriculture. Eds. Murray, J.D.; Anderson, G.B.; Oberbauer, A.M.; McGloughlin, M.M. Wallingford, CAB International.

Valancius, V.; Smithies, O. 1991. Testing an "in-out" targeting procedure for making subtle genomic modifications in mouse embryonic stem cells. Molecular and cellular biology 11: 1402-1408.
Whitelaw, C.B.A.; Springbett, A.J.; Webster, J.; Clark, J. 1993. The majority of G0 transgenic mice are derived from mosiac embryos. Transgenic research 2: 29-32.

Wu, H.; Liu, X.; Jaenisch, R. 1994. Double replacement: strategy for efficient introduction of subtle mutations into the murine Colla-1 gene by homologous recombination in embryonic stem cells. Proceedings of the National Academy of Sciences of the USA 91: 2819-2823. 
